\title{
Clinical and Histopathological Characteristics of Gastric Adenocarcinoma in Yemeni Patients: A 2 Years Prospective Study
}

\author{
Abdulgafoor Kassim¹, Saeed Thabet ${ }^{2}$, Sadik Al-Fakih ${ }^{3}$, Mohammed Alqobaty4, \\ Ramea Alathwary ${ }^{*}$, Sana Ameen ${ }^{5}$ \\ ${ }^{1}$ Gastroenterology and Hepatology, Internal Medicine, Faculty of Medicine, Taiz University, Taiz, Yemen \\ ${ }^{2}$ Hematology, Internal Medicine, Faculty of Medicine, Taiz University, Taiz, Yemen \\ ${ }^{3}$ Surgery, Surgical Department, Faculty of Medicine, Taiz University, Taiz, Yemen \\ ${ }^{4}$ Pathology, Pathology Department, Faculty of Medicine, Taiz University, Taiz, Yemen \\ ${ }^{5}$ Internal Medicine, Internal Medicine Department, Faculty of Medicine, Taiz University, Taiz, Yemen \\ Email: a.algafoor@gmail.com, saidesco@gmail.com, sadeksabri41@gmail.com, mohqub3@yahoo.com, \\ *alathwaryramea@gmail.com, sana.ameen38@yahoo.com
}

How to cite this paper: Kassim, A., Thabet, S., Al-Fakih, S., Alqobaty, M., Alathwary, R. and Ameen, S. (2018) Clinical and Histopathological Characteristics of Gastric Adenocarcinoma in Yemeni Patients: A 2 Years Prospective Study. Open Access Library Journal, 5: e5075. https://doi.org/10.4236/oalib.1105075

Received: November 27, 2018 Accepted: December 22, 2018 Published: December 25, 2018

Copyright $\odot 2018$ by authors and Open Access Library Inc.

This work is licensed under the Creative Commons Attribution International License (CC BY 4.0).

http://creativecommons.org/licenses/by/4.0/

c) (i) Open Access

\begin{abstract}
Objectives: To study the clinical and the histopathological characteristics of gastric cancer concentrating more on the gastric adenocarcinoma. Design: Prospective study of one hundred thirty Yemeni patients confirmed with gastric malignancies during the period from July 2016 to July 2018. Setting: Specialized center of gastrointestinal and liver diseases in Ibb city, Yemen. Subjects: All patients with histopathologically proved gastric cancer. Results: We collect 130 patients with gastric cancer during the study period, they were 93 males and 37 females with age ranged between 25 years and 100 years and the mean age was $64.98 \pm 15.15$ years. The most frequent clinical presentations of our patients were epigastric pain (81.5\%), weight loss (74.6\%), dysphagia (46.9\%), vomiting (49.2\%), palpable epigastric mass (19.2\%) and hematemesis/melena (20\%). Proximally located gastric cancer represented $46.1 \%$; $48.9 \%$ of males patients and $38.9 \%$ of females patients. Adenocarcinoma constituted $92.4 \%$, of which the intestinal type was $82.5 \%$ and the diffuse type was $17.5 \%$. Squamous cancer accounted in $1.5 \%$, and the non-epithelial tumor was in $6.1 \%$, of which $4.6 \%$ were lymphoma and $1.5 \%$ were GIST. Conclusion: Adenocarcinomas are the major histological type of gastric cancer and represent $92.4 \%$ of all gastric malignancies in which intestinal type represented $82.5 \%$ and diffuse type represented $17.5 \%$, and proximally located gastric cancer within stomach was the commonest in both sexes.
\end{abstract}




\section{Subject Areas}

Gastroenterology \& Hepatology

\section{Keywords}

Gastric Adenocarcinoma, Histopathology, Lauren Classification, Yemen

\section{Introduction}

Globally, the incidence and mortality of gastric cancer have fallen dramatically over the past 70 years [1] [2]. However, gastric cancer is currently the fourth most common cancer and the second leading cause of cancer-related death worldwide [3] [4]. In 2012, the World Health Organization estimated about one million new cases of gastric cancer, more than $70 \%$ of the cases $(677,000$ cases) occurred in developed countries with 2:1 male to female ratio and half of those cases were on the Asian continent mainly China [5] [6]. There are two main histologic variants of gastric adenocarcinoma: "intestinal-type" (which resembles intestinal cancers in forming glandular structures) and "diffuse" (which is poorly differentiated, has signet-ring cells, and lacks glandular formation) according to Lauren's classification [7] [8]. The intestinal type is more common in males, blacks, and older age groups, whereas the diffuse type does not show gender predominance, and is more frequent in younger individuals [1] [9] [10]. Intestinal type tumors predominate in high-risk nations of gastric cancer, such as East Asia, Eastern Europe, Central and South America [9]. Moreover diffuse type adenocarcinomas have a more uniform geographic distribution [11]. The recent decrease in the incidence of gastric cancer worldwide caused by decline in the incidence of the intestinal type tumors [9] [12]. However; the incidence of diffuse type gastric carcinoma, particularly the signet ring type, has been increasing [13]. The two main tumor sites of gastric cancer are proximal (cardia) and distal (non-cardia) and despite a dramatic decline in distal gastric cancers, proximal tumors have been increasing in incidence especially in the Western countries [1] [7] [14] [15]. They may differ in genetic susceptibility, pathologic profile, clinical presentation, and prognosis [16]. The observed differences between gastric cancers by anatomic site suggest that they are distinct diseases with different etiologies [17] [18]. Although the etiology of gastric cancer is complex, the most important and well-studied risk factors are Helicobacter pylori ( $H$. pylori) infections, environmental factors, nutritional factors and host genetic factors, such as a positive family history for gastric cancer and/or a genetic pro-inflammatory profile [1] [3] [17] [19]. Several environmental exposures have already been identified as risk factors for gastric cancer including diet, smoking, bacterial infections and a variety of occupational exposures [1] [3] [17] [20]. The effects of $H$. pylori on gastric tumor development may vary by anatomical site in which there is a strong link between $H$. pylori infection and distal gastric cancer and not the proximal one [3] [21]. Gastric cancer is generally 
asymptomatic until the disease is quite advanced [3] [17]. Symptoms of gastric cancer are nonspecific and may include anorexia, weight loss, abdominal pain or discomfort, nausea, vomiting, early satiety and gastrointestinal bleeding [3] [7] [17]. There are only a few studies regarding the epidemiologic distribution of gastric cancer in developing countries and the Middle East [22] [23] [24]. According to the $\mathrm{WHO}$, the reported incidence of gastric cancer in the neighboring countries such as Saudi Arabia in 2012 was 3.14\% [25]. It is not known whether the incidence has changed in the Middle East, and the actual epidemiologic distribution of gastric cancer according to age, sex, location within the stomach, and tumor histologic types are not fully established in this part of the world [26].

\section{Materials and Methods}

This study was carried out in Ibb city-Yemen during the period from July 2016 and July 2018 at gastrointestinal and liver diseases center. We enrolled in this study consecutive patients with histologically confirmed gastric cancer. Patients with endoscopic gastric tumor without histological confirmation were excluded. To all patients included in the study sociodemographic data, presenting symptoms, clinical findings, risk factors, ultrasonographic, endoscopic and histopathologic findings were collected. Verbal consent was also obtained from patients or their relatives. CBC, LFT, RBS, RFT, H. pylori serology and fecal Ag test were done to all patients. One experienced endoscopist performed an upper GI endoscopy using (PENTAX-EPK-5000 Unit) to all studied patients. Location, size and endoscopic appearance of the lesion were described and six biopsy specimens were minimally taken for histopathologic examination. In all cases $10 \%$ formalin was used as fixative. Histopathological examination which carried out by two independent expert pathologists. Histological classification of gastric cancer was based on Lauren's criteria [8]. Statistical analyses were performed by using SPSS version 20 sciences. Results were presented as mean $+/-$ standard deviation (SD). Nominal data were expressed by percentages. P-values $<0.05$ were considered to be statistically significant.

\section{Results}

We collected 130 patients with confirmed gastric cancer during the study period. Their demographic data and risk factors were shown in Table 1. The most frequent clinical manifestations were shown in Table 2. The anatomical site of the tumor within the stomach, the macroscopic and microscopic types were all shown in Table 3. The correlation of gastric adenocarcinoma histopathologic types with age, sex, $H$. pylori infection and location were shown in (Table 4, Table 5).

\section{Discussion}

Gastric cancer is a major health issue worldwide [17]. Adenocarcinomas represent about $90 \%$ of all gastric cancers [18]. It is subdivided into two main 
Table 1. Demographic characteristics and risk factors of our patients $(n=130)$.

\begin{tabular}{|c|c|c|c|c|c|c|c|}
\hline \multirow{3}{*}{ Characters } & \multicolumn{2}{|c|}{ Male } & \multicolumn{2}{|c|}{ Female } & \multicolumn{2}{|c|}{ Total } & \multirow[t]{3}{*}{$P$ value } \\
\hline & $\mathrm{n}$ & $(\%)$ & $\mathrm{n}$ & $(\%)$ & $\mathrm{n}$ & $(\%)$ & \\
\hline & 93 & 71.5 & 37 & 28.5 & 130 & 100 & \\
\hline Age & & & & & & & 0.29 \\
\hline Less than 40 & 4 & 4.3 & 4 & 10.8 & 8 & 6.2 & \\
\hline $40-49$ & 8 & 8.7 & 4 & 10.8 & 12 & 9.3 & \\
\hline $50-59$ & 8 & 8.7 & 4 & 10.8 & 12 & 9.3 & \\
\hline $60-69$ & 21 & 22.8 & 12 & 32.4 & 33 & 25.6 & \\
\hline$>70$ & 51 & 55.4 & 13 & 35.1 & 64 & 49.6 & \\
\hline Residence & & & & & & & 0.21 \\
\hline Rural & 83 & 89.2 & 30 & 81.1 & 113 & 86.9 & \\
\hline Urban & 10 & 10.8 & 7 & 18.9 & 17 & 13.1 & \\
\hline \multicolumn{8}{|l|}{ Risk factors } \\
\hline H. pylori & 60 & 64.5 & 23 & 62.2 & 83 & 63.8 & 0.80 \\
\hline Smoking & 52 & 55.9 & 4 & 10.8 & 56 & 43.1 & 0.00 \\
\hline Khat chewing & 73 & 78.5 & 22 & 59.5 & 95 & 73.1 & 0.03 \\
\hline $\begin{array}{c}\text { History of gastric cancer in } 1^{\text {st }} \\
\text { or } 2^{\text {nd }} \text { degree relatives }\end{array}$ & 3 & 3.2 & 1 & 2.7 & 4 & 3.1 & 0.87 \\
\hline Previous gastric surgery & 1 & 1 & 0 & 0 & 1 & 0.8 & 0.52 \\
\hline
\end{tabular}

Table 2. Clinical presentations of the studied patients $(n=130)$.

\begin{tabular}{cccccccc}
\hline \multirow{2}{*}{ Clinical manifestations } & \multicolumn{2}{c}{ Male } & \multicolumn{2}{c}{ Female } & \multicolumn{3}{c}{ Total } \\
\cline { 2 - 8 } & $\mathrm{n}$ & $(\%)$ & $\mathrm{n}$ & $(\%)$ & $\mathrm{n}$ & $(\%)$ \\
\hline Epigastric pain & 74 & 79.6 & 32 & 86.5 & 106 & 81.5 \\
Weight loss & 73 & 78.5 & 24 & 64.9 & $\mathbf{9 7}$ & 74.6 \\
dyspepsia & 59 & 63.4 & 26 & 70.3 & $\mathbf{8 5}$ & 65.4 \\
Vomiting & 44 & 47.3 & 20 & 54.1 & $\mathbf{6 4}$ & 49.2 \\
Dysphagia & 43 & 46.2 & 18 & 48.6 & 61 & 46.9 \\
Postprandial fullness & 19 & 20.4 & 13 & 35.1 & 32 & 24.6 \\
Upper GIT bleeding & 19 & 20.4 & 7 & 18.9 & 26 & 20 \\
Palpable epigastric mass & 22 & 23.7 & 3 & 8.1 & 25 & 19.2 \\
\hline
\end{tabular}

histologic types; intestinal and diffuse type [7] [8] [18]. The incidence of intestinal-type adenocarcinoma has declined significantly, but it is still the most common type (70\% - 80\%) [7]. There are little studies in Yemen that classify and study adenocarcinoma by subtypes. In our study 130 cases of confirmed gastric cancer were identified between July 2016 to July 2018 which may denote an increasing incidence of gastric cancer in our country as compared to the reported data from neighboring countries [27] [28]. The mean age of our studied patients was of $64.98 \pm 15.15$ years with a range between $25-100$ years. The mean age for males was of $67.31 \pm 14.39$ and was of $58.84 \pm 15.65$ for females. Over $70 \%$ of 
Table 3. Anatomical site, macroscopic appearance and histopathological types $(n=130)$.

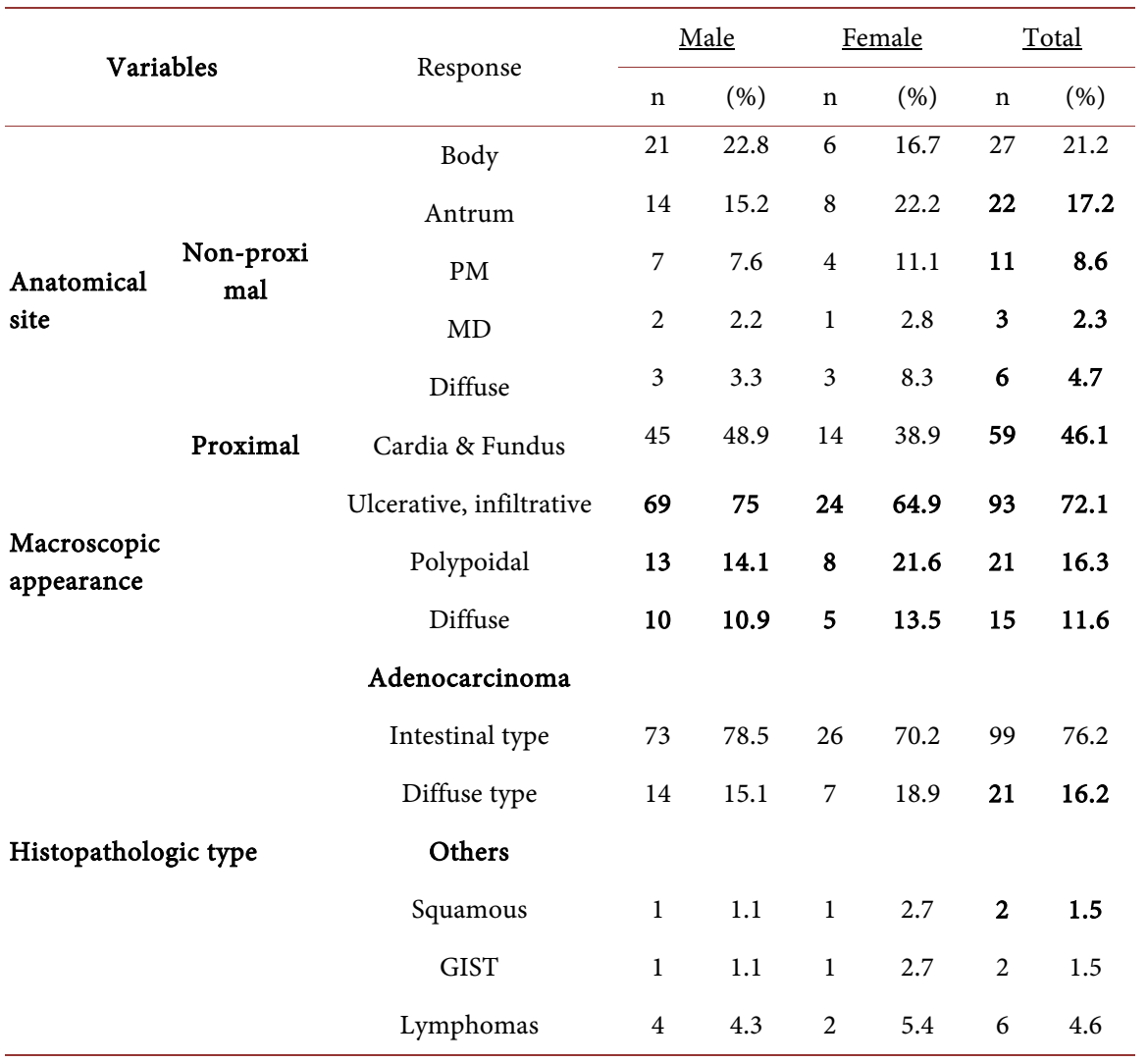

$\mathrm{PM}=$ Proximal and middle part of the stomach. $\mathrm{MD}=$ middle and distal part of the stomach.

Table 4. Histopathological classification of gastric adenocarcinoma in correlation with $\operatorname{sex}($ no $=120)$.

\begin{tabular}{cccccccc}
\hline \multirow{2}{*}{ Histopathological type } & \multicolumn{2}{c}{ Male } & \multicolumn{2}{c}{ Female } & \multicolumn{2}{c}{ Total } \\
\cline { 3 - 8 } & Well differentiated & 27 & 31.0 & 11 & 33.3 & $\mathbf{3 8}$ & 31.7 \\
& Moderate differentiated & 10 & 11.5 & 4 & 12.1 & $\mathbf{1 4}$ & 11.7 \\
\multirow{3}{*}{ Intestinal type } & poorly differentiated & 28 & 32.2 & 8 & 24.2 & 36 & $\mathbf{3 0}$ \\
& Mucinous & 7 & 8 & 1 & 3 & $\mathbf{8}$ & $\mathbf{6 . 7}$ \\
& Papillary & 1 & 1.1 & 2 & 6.1 & $\mathbf{3}$ & $\mathbf{2 . 5}$ \\
Diffuse type & Undifferentiated & 6 & 6.9 & 2 & 6.1 & $\mathbf{8}$ & $\mathbf{6 . 7}$ \\
Total & Signet cell ca & 8 & 9.2 & 5 & 15.2 & $\mathbf{1 3}$ & $\mathbf{1 0 . 8}$ \\
& & 87 & 100 & 33 & 100 & $\mathbf{1 2 0}$ & $\mathbf{1 0 0}$ \\
\hline
\end{tabular}

male patients and over $60 \%$ of female patients were over 60 years of age and this is in consistent with those reported for patients from high risk countries and medical literatures [17] [18] [26] [27] [28]. Male to female ratio in our study was 2.5:1 which is similar to what is known in the medical literatures and previous studies from our country and neighboring counties [3] [17] [18] [29] [30] [31] [32]. The risk factors studied in our research were $H$. pylori infection, khat 
Table 5. Correlation of gastric adenocarcinoma $(n=120)$ with age, sex, H pylori infection \& tumor location.

\begin{tabular}{|c|c|c|c|c|c|c|c|c|c|c|c|}
\hline \multirow{3}{*}{$\begin{array}{c}\text { Histological } \\
\text { types }\end{array}$} & \multirow{3}{*}{$\begin{array}{c}\text { Age (years) } \\
\text { Mean }\end{array}$} & \multicolumn{4}{|c|}{ Sex } & \multirow{2}{*}{\multicolumn{2}{|c|}{ H pylori nfection }} & \multicolumn{4}{|c|}{ Location } \\
\hline & & \multicolumn{2}{|c|}{ Male } & \multicolumn{2}{|c|}{ Female } & & & \multicolumn{2}{|c|}{ Proximal } & \multicolumn{2}{|c|}{ Distal } \\
\hline & & No & $\%$ & no & $\%$ & no & $\%$ & no & $\%$ & no & $\%$ \\
\hline Intestinal & $65.12 \pm 15.1$ & 73 & 84.9 & 26 & 81.3 & 65 & 65.7 & 50 & 50.5 & 49 & 49.5 \\
\hline Diffuse & $67.6 \pm 13.2$ & 13 & 15.1 & 6 & 18.8 & 13 & 68.4 & 8 & 42.1 & 11 & 57.9 \\
\hline Total & $65.5 \pm 14.8$ & 86 & 100 & 32 & 100 & 78 & 66.1 & 58 & 49.2 & 60 & 50.8 \\
\hline$P$ value & 0.83 & \multicolumn{4}{|c|}{0.51} & \multicolumn{2}{|c|}{0.92} & \multicolumn{4}{|c|}{0.81} \\
\hline
\end{tabular}

chewing, smoking and others (Table 1). H. pylori infection prevalence in developing countries including Yemen ranges between $70 \%$ and $90 \%$ in adult population [33] [34], compared to a much lower prevalence in developed countries such as USA where the prevalence is $<20 \%$ at the age of 20 years and $50 \%$ at 50 years [35]. It has been reported in Yemen that the prevalence of $H$. pylori infection among patients underwent upper GIT endoscopy in Sana'a major hospitals was very high (99.6\%) [36]; however prevalence data for the general population are lacking. In our studied patients the $H$. pylori seropositivity was seen in $63.8 \%$. This high prevalence of $H$. pylori infection in addition to other risk factors could explain the increasing incidence of gastric cancer in our country. Smoking is a risk factor for many cancers [37]. A significant relationship between smoking and gastric cancer was reported in many studies [38] [39] [40] [41]. In a large population-based study in Europe (EPIC), $17.6 \%$ of gastric cancer cases were attributed to smoking [39]. In our study smoking was encountered in $43.1 \%$ more in males (55.9\%) than in females (10.8\%). Khat chewing habit became very common in Yemen where approximately $60 \%-90 \%$ of males and $35 \%$ of females chew Khat daily [42]. Chemically khat leaves contains cathinone (S-(-)-a-aminopropiophenone) and cathine (S, S-(-)-norpseudoephedrine [41]. Farmers used many kinds of pesticides mostly in illegal way for most of the cultivated plants including Khat. Khat chewing was reported in many studies to be a risk factor in many disorders including cancers [43]. In our study $73.1 \%$ (78.5\% of males and $59.5 \%$ of females) were chewed Khat. There is statistically significant differences regarding smoking and Khat chewing with sex $(\mathrm{P}$ value $=$ 0.00 and 0.03 respectively) in which smoking and Khat chewing were more in males (Table 1). The proximal gastric cancer was found to be the most common in our community in both males and females, accounting for $48.9 \%$ of male patients and $39.9 \%$ of female patients, this is similar to the reported studies from western countries and our previous study and medical literatures [3] [15] [44] [45], but not in agreement with many studies from developing countries [28] [46] [47]. In developed countries, increasing cardia gastric cancer was believed to be due to reduction in the incidence of $H$. pylori infection and subsequently reduction in the distally located gastric cancer at the expense of the proximal one 
[3]. In our country $H$. pylori infection incidence still high and despite of this, the proximal location in our studied patients was the commonest (Table 3). This may reflect emerging of new risk factors in our community such as chewing khat habit and/or the pesticides used in it and in mostly all kinds of vegetables and fruits cultured in our country, as it is already reported in some studies [48]. The most frequent symptoms reported by stomach cancer patients in the present study were abdominal pain (81.5\%), weight loss (74.6\%), dyspepsia (65.4\%), vomiting (49.2\%) and dysphagia (46.9\%) Table 2. The proportions of presenting symptoms in the present study are much higher than those reported by Selcukbiricik et al. [49]. Because of active screening programs in Eastern Asia, and developed world many patients are now detected while asymptomatic [50]. However, most patients with gastric cancer in our country are presented in advanced stages as indicated by the high percentage (46.9\%) of patients presented with dysphagia in this study and other studies from Yemen [32] [44]. This could be attributed to the poverty and a little accessibility to the available specialized health care centers in one hand, and lack of active screening programs and policies in the country on the other hand.

Analyzing the histologic subtypes of gastric cancer in our patients, gastric adenocarcinoma was found in 120 (92.3\%); where the intestinal type seen in 99 cases $(82.5 \%)$ and diffuse type seen in 21 cases (17.5\%) and the other types of gastric cancer were lymphoma in $4.6 \%$, GIST in $1.5 \%$ and squamous type in $1.5 \%$ (Table 3 ) and this is similar to some degree with studies from our country and neighboring area [32] [44] [51], and in discordance with M.G. Martínez-Galindo et al in which diffuse-type adenocarcinoma was reported in $55.2 \%$, intestinal-type in $28.2 \%$ [52]. This difference between our study results and the results of M.G. Martínez-Galindo et al could be explained by using different classification system. In our study tubular adenocarcinoma was the predominant type seen in $88(73.4 \%)$ patients in which well differentiated grade seen in 38 (31.7\%), moderately differentiated in 14 (11.7\%) and poorly differentiated in $36(30 \%)$. This was followed by signet ring cell, mucinous, undifferentiated and papillary adenocarcinoma in 13 (10.8\%), 8 (6.7\%), 8 (6.7\%) and 3 (2.5\%) respectively. This is consistent with other studies in Yemen [44] [51]. We compared between intestinal and diffuse type adenocarcinoma regarding the mean age, sex, H. pylori infection and location of the tumor and we found no significant statistical differences between intestinal and diffuse type regarding all studied variables as $\mathrm{P}$ value was $>0.05$ (Table 5), and this is in agreement with a study from KSA done by Hamdi et al. regarding the mean age and sex [53], but not in agreement with what is known in the global literatures and other studies [3] [7] [53]. This difference should be further investigated considering various geographical and demographical features of our country.

\section{Conclusions}

Clinical and pathological characteristics of gastric adenocarcinoma among Ye- 
meni patients are somewhat similar to those in other parts of the world.

Histopathologically, intestinal-type adenocarcinoma with their different sub-types was the most common types of stomach cancers among Yemeni patients.

Proximally located gastric cancer is more frequent in our patients in both sexes.

\section{Conflicts of Interest}

The authors declare no conflicts of interest regarding the publication of this paper.

\section{References}

[1] Katherine, D.C. and Alfred, I.N. (2006) Epidemiology of Gastric Cancer. World Journal of Gastroenterology, 12, 354-362. https://doi.org/10.3748/wjg.v12.i3.354

[2] Parkin, D.M., Pisani, P. and Ferlay, J. (1993) Estimates of the Worldwide Incidence of Eighteen Major Cancers in 1985. International Journal of Cancer, 54, 594-606. https://doi.org/10.1002/ijc.2910540413

[3] Parveen, K. and Kumar, M.C. (2012) Clark's Clinical Medicine. $8^{\text {th }}$ Edition, Vol. 1, Elsevier, UK, 251-253.

[4] Felix, B., Elfriede, B., Uta, D., Arnulf, H.H. and Stefan, M. (2014) Pathohistological Classification Systems in Gastric Cancer: Diagnostic Relevance and Prognostic Value. World Journal of Gastroenterology, 20, 5679-5684. https://doi.org/10.3748/wjg.v20.i19.5679

[5] Globocan (2012) Estimated Cancer Incidence, Mortality and Prevalence Worldwide in 2012. World Health Organization.

[6] Junli, M., Hong, S., Linda, K. and Shan, Z. (2016) Lauren Classification and Individualized Chemotherapy in Gastric Cancer (Review). Oncology Letters, 11, 2959-2964. https://doi.org/10.3892/ol.2016.4337

[7] Maxine, A.P., Stephen, J.M. and Michael, W.R. (2019) Current Medical Diagnosis \& Treatment. 58th Edition, Vol. 1, McGraw-Hill Education, New York, 1641-1644.

[8] Lauren, T. (1965) The Two Histological Main Types of Gastric Carcinoma. Acta Pathologica Microbiologica Scandinavica, 64, 34.

https://doi.org/10.1111/apm.1965.64.1.31

[9] Pelayo, C. and Blanca, P. (2011) Helicobacter pylori Infection and Gastric Adenocarcinoma. US Gastroenterol Hepatol Rev., 7, 59-64.

[10] Lauren, P. (1965) The Two Histological Main Types of Gastric Carcinoma: Diffuse and So-Called Intestinal-Type Carcinoma. An Attempt at a Histo-Clinical Classification. Acta Pathologica Microbiologica Scandinavica, 64, 31-49. https://doi.org/10.1111/apm.1965.64.1.31

[11] Muñoz, N., Correa, P., Cuello, C. and Duque, E. (1968) Histologic Types of Gastric Carcinoma in High- and Low-Risk Areas. International Journal of Cancer, 3, 809-818. https://doi.org/10.1002/ijc.2910030614

[12] Kaneko, S. and Yoshimura, T. (2001) Time Trend Analysis of Gastric Cancer Incidence in Japan by Histological Types, 1975-1989. British Journal of Cancer, 84, 400-405. https://doi.org/10.1054/bjoc.2000.1602

[13] Henson, D.E., Dittus, C., Younes, M., Nguyen, H. and Albores-Saavedra, J. (2004) Differential Trends in the Intestinal and Diffuse Types of Gastric Carcinoma in the United States, 1973-2000: Increase in the Signet Ring Cell Type. Archives of Pathology \& Laboratory Medicine, 128, 765-770. 
[14] Blot, W.J., Devesa, S.S., Kneller, R.W. and Fraumeni, J.F. (1991) Rising Incidence of Adenocarcinoma of the Esophagus and Gastric Cardia. JAMA, 265, 1287-1289. https://doi.org/10.1001/jama.1991.03460100089030

[15] Brown, L.M. and Devesa, S.S. (2002) Epidemiologic Trends in Esophageal and Gastric Cancer in the United States. Surgical Oncology Clinics, 11, 235-256.

[16] Shen, H., Xu, Y., Qian, Y., Yu, R., Qin, Y., Zhou, L., Wang, X., Spitz, M.R. and Wei, Q. (2000) Polymorphisms of the DNA Repair Gene XRCC1 and Risk of Gastric Cancer in a Chinese Population. International Journal of Cancer, 88, 601-606. https://doi.org/10.1002/1097-0215(20001115)88:4<601::AID-IJC13>3.0.CO;2-C

[17] Dan, L.L., Dennis, L.K., Larry, J., Anthony, S.F., Stephen, L.H. and Joseph, L. (2012) Harrison's Principle of Internal Medicine. 18th Edition, Vol. 2, John Kretschmer, New York, 765-767.

[18] Christine, A.L.D., Elizabeth, M. and John, R.G. (2012) Gastrointestinal and Liver Pathology. 2nd Edition, Vol. 1, John R. Goldblum, Philadelphia, 150-157.

[19] Lee, Y.Y. and Derakhshan, M.H. (2013) Environmental and Lifestyle Risk Factors of Gastric Cancer. Archives of Iranian Medicine, 16, 358-365.

[20] Reza, M., Mohammad, H.D. and Zinab, M. (2009) Gastric Cancer in Iran: Epidemiology and Risk Factors. Archives of Iranian Medicine, 12, 576-583.

[21] Simán, J.H., Forsgren, A., Berglund, G., et al. (1997) Association between Helicobacter pylori Infection and Gastric Carcinoma in the City of Malmo, Sweden. A Prospective Study. Scandinavian Journal of Gastroenterology, 32, 1215-1221. https://doi.org/10.3109/00365529709028150

[22] Bani-Hani, K., Yaghan, R., Heis, H., Shatnawi, N., Katalka, I., Bani-Hani, A., et al. (2004) Gastric Malignancies in Northen Jordan with Special Emphasis on Descriptive Epidemiology. World Journal of Gastroenterology, 10, 2174-2178. https://doi.org/10.3748/wjg.v10.i15.2174

[23] Raha, A., Osman, H., Al-Enizi, H. and Tashkandi, A. (2016) Incidence of Gastric Carcinoma at King Faisal Specialist Hospital-Jeddah Saudi Arabia: A Hospital-Based Study. Integrative Molecular Medicine, 3, 606-611. https://doi.org/10.15761/IMM.1000211

[24] El Hassan, A., El Hassan, L., Mudawi, H., Gasim, B., Own, A., Elamin, E., Ibn Ouf, M., et al. (2008) Malignant Gastric Tumors in Sudan: A Report from a Single Pathology Center. Hematology/Oncology and Stem Cell Therapy, 1, 130-132. https://doi.org/10.1016/S1658-3876(08)50044-6

[25] International Agency for Research on Cancer (2012) Globocan, Cancer Incidence, Mortality and Prevalence Worldwide. International Agency for Research on Cancer, Lyon.

[26] Heyam, A.A., Manar, H.H., Mohand, W.A., Mohammad, A.A. and Ali, A.A. (2017) Epidemiologic Characteristics of Gastric Malignancies among Jordan University Hospital Patients. Saudi Medical Journal, 38, 965-967. https://doi.org/10.15537/smj.2017.9.19371

[27] Haitham Al-Mahrouqi, L.P. and Sharples, K. (2011) Incidence of Stomach Cancer in Oman and the Other Gulf Cooperation Council Countries. Oman Medical Journal, 26, 58-62.

[28] David, A.S., Abdul-Basit, A., Mohammad, I., Abdul-Rauf, K. and Abdul-Naser, A.B. (1995) Gastric Cancer: A Clinicopathological Analysis of 54 Cases Seen at Asir Central Hospital. Saudi Medical Journal, 16, 308-311.

[29] Surveillance, Epidemiology, and End Results Program. SEER Stat Fact Sheets: Sto- 
mach Cancer. National Cancer Institute.

[30] Ferlay, J., Shin, H.R., Bray, F., Forman, D., Mathers, C., et al. (2010) Estimates of Worldwide Burden of Cancer in 2008: GLOBOCAN 2008. International Journal of Cancer, 127, 2893-2917. https://doi.org/10.1002/ijc.25516

[31] Office for National Statistics (2015) Cancer Statistics Registration, England: 2013. https://www.ons.gov.uk/peoplepopulationandcommunity/healthandsocialcare/cond itionsanddiseases/bulletins/cancerregistrationstatisticsengland/2015-07-10

[32] Abdulla, S.A. and Saleh, M.A. (2013) Histopathology of Gastric Cancer in Yemen Seven Years Retrospective Analysis. Sudan JMS, 8, 91-92.

[33] Al-Moagel, M.A., Evans, D.G., Abdulghani, M.E., Adam, E., Evans, D.J., Malaty, H.M., et al. (1990) Prevalence of Helicobacter pylori (Formerly Campylobacter) Infection in Saudi Arabia, and Comparison of Those with and without Upper Gastrointestinal Symptoms. The American Journal of Gastroenterology, 85, 944-948.

[34] Al-Makdad, A.M., Al-Dholaee, M.H., Thabet, A.A.K., Al-Haimi, M.A., Balfaqih, O.S. and Al-Hadad, A.M. (2013) Prevalence of Helicobacter pylori Infection in Yemeni Patients. Yemeni Journal for Medical Sciences, 7, 37.

[35] Graham, D.Y., Malaty, H.M., Evans, D.G., Evans, D.J., Klein, P.D. and Adam, E. (1991) Epidemiology of Helicobacter pylori in an Asymptomatic Population in the United States. Effect of Age, Race, and Socioeconomic Status. Gastroenterology, 100, 1495-1501. https://doi.org/10.1016/0016-5085(91)90644-Z

[36] Al-Shami, H.Z. (2002) Prevalence of Helicobacter pylori Infection among Patients Underwent Upper Gastrointestinal Tract Endoscopy in Sana'a Major Hospitals. Thesis in MSc, Faculty of Medicine, Sana'a University, Yemen.

[37] Doll, R., Peto, R., Boreham, J. and Sutherland, I. (2005) Mortality from Cancer in Relation to Smoking: 50 Years Observations on British Doctors. British Journal of Cancer, 92, 426-429. https://doi.org/10.1038/sj.bjc.6602359

[38] Sjödahl, K., Lu, Y., Nilsen, T.I., Ye, W., Hveem, K., Vatten, L., et al. (2007) Smoking and Alcohol Drinking in Relation to Risk of Gastric Cancer: A Population-Based, Prospective Cohort Study. International Journal of Cancer, 120, 128-132. https://doi.org/10.1002/ijc.22157

[39] González, C.A., Pera, G., Agudo, A., Palli, D., Krogh, V., Vineis, P., et al. (2003) Smoking and the Risk of Gastric Cancer in the European Prospective Investigation into Cancer and Nutrition (EPIC). International Journal of Cancer, 107, 629-634. https://doi.org/10.1002/ijc.11426

[40] Ghadimi, R., Taheri, H., Suzuki, S., Kashifard, M., Hosono, A., Esfandiary, I., et al. (2007) Host and Environmental Factors for Gastric Cancer in Babol, the Caspian Sea Coast, Iran. European Journal of Cancer Prevention, 16, 192-195. https://doi.org/10.1097/01.cej.0000220639.61717.67

[41] Koizumi, Y., Tsubono, Y., Nakaya, N., Kuriyama, S., Shibuya, D., Matsuoka, H., et al. (2004) Cigarette Smoking and the Risk of Gastric Cancer: A Pooled Analysis of Two Prospective Studies in Japan. International Journal of Cancer, 112, 1049-1055. https://doi.org/10.1002/ijc.20518

[42] Balint, E.E., Falkay, G. and Balint, G.A. (2009) Khat: A Controversial Plant. Wiener Klinische Wochenschrift, 121, 604-614. https://doi.org/10.1007/s00508-009-1259-7

[43] Hassan, N.A.G.M., Gunaid, A.A. and Murray-Lyon, I.M. (2007) Khat (Catha edulis): Health Aspects of Khat Showing. La Revue de santé de la Méditerranée Orientale, 13, 706-717.

[44] Abdulgafoor, K., Mohammed, A., Fayed, A., Ramea, A. and Sana, A. (2018) Clini- 
copathological Pattern of Gastric Cancer of Yemeni Patients in Ibb Governorate. Open Access Library Journal, 5, 1-10. https://doi.org/10.4236/oalib.1104415

[45] Selcukbiricik, F., Buyukunal, E., Tural, D., Ozguroglu, M., Demirelli, F. and Serdengecti, S. (2013) Clinicopathological Features and Outcomes of Patients with Gastric Cancer: A Single-Center Experience. World Journal of Gastroenterology, 19, 2154-2161. https://doi.org/10.3748/wjg.v19.i14.2154

[46] Nassima, C., Khan, A.R., Romana, M. and Saud, L. (2007) Histopathology of Gastric Cancer in Kashmir-A Five Year Retrospective Analysis. JK Science, 9, 21-24.

[47] Miomir, P., Aleksandar, K., Nebojsa, D., Vuka, K., Zoran, R., Milan, R., Nikola, I. and Ivan, P. (2004) The Importance of Primary Gastric Cancer Location in 5-Year Survival Rate. Arch Oncology, 12, 51.

[48] Ejaz, S., Akram, W., Lim, C.W., et al. (2004) Endocrine Disrupting Pesticides: A Leading Cause of Cancer among Rural People in Pakistan. Experimental Oncology, 26, 98-105.

[49] Acraanen, M.E., Dekker, W., Ferw erda, J., Bolk, P. and Tytqat, G.N. (1991) Early Gastric Cancer: A Clinicopathologic Study. Journal of Clinical Gastroenterology, 13, 274-283. https://doi.org/10.1097/00004836-199106000-00006

[50] Waleed, M.A.G., Mohammed, A.A. and Taha, B. (2017) Clinicopathologic Characteristics of Stomach Cancer among Patients Admitted to the Surgical Departments of Teaching Hospitals in Sana'a, Yemen. Yemeni Journal for Medical Sciences, 11, $38-45$.

[51] Martínez-Galindo, M.G., Zamarripa-Dorsey, F., Carmona-Castaneda, A., Angeles-Labra, A., Penavera-Hernández, R., Ugarte-Briones, C. and Blanco-Vela, C.I. (2015) Histopathologic Characteristics of Gastricadenocarcinoma in Mexican Patients: A 10-Year Experience at the Hospital Juárez de México. Revista de Gastroenterología de México, 80, 21-26. https://doi.org/10.1016/j.rgmx.2014.11.002

[52] Hamdi, J. and Morad, N.A. (1994) Gastric Cancer in Southern Saudi Arabia. Annals of Saudi Medicine, 14, 195-197.

[53] Ashis, K.S., Somnath, M. and Subhas, C.H. (2013) Epidemiology of Gastric Cancer in the Gangetic Areas of West Bengal. Gastroenterology, 2013, Article ID: 823483. https://doi.org/10.1155/2013/823483 